\title{
Reinterventions following laparoscopic cholecystectomy and bile duct exploration. A review of prospective data from 5740 patients
}

\author{
Hwei Jene $\mathrm{Ng}^{1} \cdot$ Ahmad H. M. Nassar ${ }^{2}$ D \\ Received: 12 January 2021 / Accepted: 18 May 2021 / Published online: 2 June 2021 \\ (C) The Author(s) 2021
}

\begin{abstract}
Background Complications following laparoscopic cholecystectomy (LC) and common bile duct exploration (CBDE) for the management of gallstones or choledocholithiasis impact negatively on patients' quality of life and may lead to reinterventions. This study aims to evaluate the causes and types of reintervention following index admission LC with or without CBDE. Methods A prospectively maintained database of $\mathrm{LC}$ and CBDE performed by a single surgeon was analysed. Preoperative factors, difficulty grading and perioperative complications requiring reintervention and readmissions were examined.

Results Reinterventions were required in 112 of 5740 patients (2.0\%), 89 (1.6\%) being subsequent to complications. The reintervention cohort had a median age of 64 years, were more likely to be females $(p<0.0023)$ and to be emergency admissions $(67.9 \%, p<0.00001)$ with obstructive jaundice $(35.7 \%, p<0.00001) .46 .4 \%$ of the reintervention cohort had a LC operative difficulty grade IV or V and 65.2\% underwent a CBDE. Open conversion was predictive of the potential for reintervention $(p<0.00001)$. The most common single cause of reintervention was retained stones $(0.5 \%)$ requiring ERCP followed by bile leakage $(0.3 \%)$ requiring percutaneous drainage, ERCP and relaparoscopy. Relaparoscopy was necessary in 17 patients and open surgery in 13, 6 of whom not resulting from complications. There were 5 deaths.

Conclusion This large series had a low incidence of reinterventions resulting from complications in spite of a high workload of index admission surgery for biliary emergencies and bile duct stones. Surgical or endoscopic reinterventions following LC alone occurred in only $0.8 \%$. The most common form of reintervention was ERCP for retained CBD stones. This important outcome parameter of laparoscopic biliary surgery can be optimised through early diagnosis and timely reintervention for complications.
\end{abstract}

Keywords Laparoscopic cholecystectomy $\cdot$ Reintervention $\cdot$ Complications $\cdot$ Bile duct exploration

\section{Background}

Complications following laparoscopic cholecystectomy and intraoperative cholangiography (IOC) with or without common bile duct exploration (CBDE) pose various diagnostic and management challenges to the surgeon and impact negatively on the patient's quality of life. The nature and severity

Preregistration of study: No preregistration exists for the reported studies reported in this article.

Ahmad H. M. Nassar

Ahmad.nassar@glasgow.ac.uk; anassar@doctors.org.uk

1 Laparoscopic Biliary Surgery Service, University Hospital Monklands, Airdrie, Scotland, UK

2 University Hospital Monklands, Airdrie, Scotland ML6 0JS, UK of a complication will dictate the urgency with which it is to be investigated and determine whether conservative management will be sufficient to remedy that complication. Occasionally, reintervention is necessary to either improve the outcome or to avoid serious life threatening consequences.

Reintervention following LC and CBDE ranges from placing one suture to control port site bleeding to laparotomy and biliary reconstruction for a bile duct injury. Although most studies addressing biliary surgery report their complications and reinterventions, the last large study focusing on reinterventions as an outcome parameter following $\mathrm{LC}$ was published in 2002 [1].

We aim to review the causes of reinterventions following index admission LC, IOC and, when necessary, CBDE in a large series performed by a single surgeon providing a specialised acute biliary service with a high emergency workload. The secondary aim was to report the causes of 
reinterventions in patients who have not suffered any complications, a group that is usually overlooked in the literature.

\section{Methods}

A prospectively maintained database of emergency and elective patients undergoing $\mathrm{LC}$ with or without CBDE performed by a single surgeon (AHMN) or by his trainees under direct on table supervision between 1992 and 2020 was reviewed. Data on patient demographics, type of admission, clinical presentation, admission to referral and referral to surgery intervals, operative difficulty grading, open conversion, perioperative complications, reinterventions, readmissions within one year and the 30-day mortality were analysed. The operative difficulty grade was based on the Nassar Scale [2-4]. This is a five grade system of describing the operative findings according to the adhesions around the gallbladder, the state of the cystic pedicle and the condition of the gallbladder. The objective assessment of operative complexity facilitates audit, research, assessment of training and comparison between studies. The referral pathways and operative techniques have been described in detail in previous studies [5-8].

Informed consent was obtained from all patients with emphasis on the specialisation of the unit with regard to the management of suspected bile duct stones. Ethical approval was not required as the management protocols were in line with the guidelines and recommendations of national and international societies.

Statistical analysis: Categorical variables are expressed as $n$ and percentage (\%) and continuous as mean \pm standard deviation. Student's t test was used for continuous variables and Chi-square or Fisher's Exact test for categorical variables. $P$ value of $<0.05$ was considered statistically significant. All analyses were performed using IBM SPSS 22.

\section{Results}

Of the 5740 patients, $112(2.0 \%)$ patients required 157 postoperative reinterventions using different modalities. The complication rate in the whole series was $4.9 \%$, but only 89 patients (1.6\%) had suffered operative or postoperative complications requiring 110 reinterventions. 23 patients $(0.4 \%)$ needed 47 reinterventions indicated by reasons other than complications. 39 reinterventions occurred in 4422 patients who underwent LC without CBDE (0.8\%). Of these surgical reintervention was only resorted to in 10 patients $(0.2 \%)$.

The median age was 64 years (21-88 years) and the male to female ratio was $1: 1.6$. $67.9 \%$ of this patient cohort was emergency admissions. The primary admission diagnosis was jaundice in $35.7 \%$ and 32 (28.6\%) had previous emergency biliary admissions, most before being referred to the biliary unit. The original operation was performed within five days of admission in $86.6 \%$ of the patients. Demographic characteristics and preoperative data of this cohort are shown in Table 1.

$46.4 \%$ of the patients requiring reintervention had operative difficulty grades IV or V (compared to only $15.7 \%$ in the rest of the series). Most LC/CBDEs were performed by the consultant. In this cohort, 65.2\% had CBDE; 51 (69.9\%) via choledochotomy and $22(30.1 \%)$ by transcystic exploration. The perioperative findings are summarised in Table 2 .

It is interesting that acute cholecystitis and gallbladder empyema were not significant risk factors for reintervention, while the presence of Hartmann's pouch stones or contracted gallbladder were significant.

Five patients $(4.6 \%)$ in this reintervention cohort had been converted from laparoscopic to open surgery: 3 due to

Table 1 Demographic and preoperative data of patients needing postoperative reintervention

\begin{tabular}{|c|c|}
\hline Preoperative characteristics & $\begin{array}{l}\text { Reinterven- } \\
\text { tions }(n=112) \\
(\%)\end{array}$ \\
\hline \multicolumn{2}{|l|}{ Gender } \\
\hline Male & $43(38.4 \%)$ \\
\hline Female & $69(61.6 \%)$ \\
\hline \multicolumn{2}{|l|}{ Type of admissions } \\
\hline Emergency & $76(67.9 \%)$ \\
\hline Electives & $36(32.1 \%)$ \\
\hline \multicolumn{2}{|l|}{ Source of referral } \\
\hline Other surgical teams & $52(46.4 \%)$ \\
\hline Biliary team & $37(33.0 \%)$ \\
\hline Other hospitals & $17(15.2 \%)$ \\
\hline Physicians & $6(5.4 \%)$ \\
\hline \multicolumn{2}{|l|}{ Primary admission diagnosis } \\
\hline Jaundice & $40(35.7 \%)$ \\
\hline Chronic biliary colic & $33(29.5 \%)$ \\
\hline Cholangitis & $12(10.7 \%)$ \\
\hline Acute biliary colic & $13(11.6 \%)$ \\
\hline Acute pancreatitis & $7(6.3 \%)$ \\
\hline Acute cholecystitis & $7(6.3 \%)$ \\
\hline Diagnosis of previous biliary admissions & $N=32(28.6 \%)$ \\
\hline Jaundice & $10(31.3 \%)$ \\
\hline Acute pain & $10(31.3 \%)$ \\
\hline Acute cholecystitis & $10(31.3 \%)$ \\
\hline Acute pancreatitis & $2(6.3 \%)$ \\
\hline \multicolumn{2}{|c|}{ Interval between referral/ admission to surgery (day) } \\
\hline $0-1$ & $68(60.7 \%)$ \\
\hline $2-5$ & $29(25.9 \%)$ \\
\hline $6-10$ & $10(8.9 \%)$ \\
\hline$>10$ & $1(0.9 \%)$ \\
\hline No records & $4(3.6 \%)$ \\
\hline
\end{tabular}


Table 2 Perioperative characteristics of patients needing postoperative reintervention

\begin{tabular}{ll}
\hline Operative Characteristics & Patients $(n=112)(\%)$ \\
\hline Operative difficulty grade & \\
Grade 1 & $13(11.6 \%)$ \\
Grade 2 & $26(23.2 \%)$ \\
Grade 3 & $21(18.8 \%)$ \\
Grade 4 & $40(35.7 \%)$ \\
Grade 5 & $12(10.7 \%)$ \\
Operator & \\
Consultant & $93(83.0 \%)$ \\
Trainee & $19(17.0 \%)$ \\
CBD exploration & \\
Yes & $73(65.2 \%)$ \\
No & $39(34.8 \%)$ \\
Conversion to open & $5(4.5 \%)$ \\
Length of surgery, median (range) & $120(32-390)$ minutes \\
Mortality & $5(4.5 \%)$ \\
Length of hospital stay, median (range) & $16(1-160)$ days \\
Readmissions & $27(24.1 \%)$ \\
Number of episodes, median (range) & $2(1-8)$ \\
Presentation to resolution, median (range) & $5(1-56)$ weeks \\
\hline
\end{tabular}

dense adhesion and 2 due to multiple large impacted CBD stones. Three subsequently underwent ERCP for retained CBD stones and two needed percutaneous drainage of subphrenic abscesses.

ERCP was the most common postoperative biliary reintervention. $64(1.1 \%)$ patients required a total of 97 ERCPs post LC or CBDE. 15 of these patients did not have ERCP as a result of complications: eight were in the course of managing pancreatic cancers/ periampullary lesions discovered on IOC, five for the management of benign biliary strictures and two for the removal of stents. ERCP was required in 26 patients to extract retained CBD stones (21 after CBDE and 5 after LC) and in 2 for suspected CBD stones. 13 ERCPs were needed for the management of bile leakage and one to remove a biliary drain that had retracted into the abdomen. Other causes are summarised in Table 3.

Further surgical intervention was necessary in 30 (0.5\%) patients: 17 relaparoscopies and 13 by open surgery. Reoperation by open surgery included 6 patients who had not had any complications: five with incidental pancreatic, periampullary and gallbladder cancers discovered on IOC during LC and CBDE and one with Type IV Mirizzi Syndrome requiring bilioenteric bypass. All the initial procedures had been concluded laparoscopically and the patients were subsequently referred to specialised units for resection and/or biliary reconstruction.

Three patients had complications requiring remedial open surgery at specialist liver units. Two required biliary reconstruction the day after $\mathrm{LC}$ due to iatrogenic CBD injuries. One patient had an exploration and T-Tube placement for a Type III Mirizzi Syndrome and subsequently developed bile leakage and bleeding requiring reoperation and biliary bypass. Two patients with peripheral vascular disease developed acute total mesenteric ischaemia a few days after laparoscopic biliary surgery, and laparotomies revealed nonsalvageable total bowel infarction. Two had laparotomies for colonic perforations: one with an iatrogenic injury due to adhesiolysis and one with a coincidental perforation of an undiagnosed colonic tumour, both developed severe sepsis.

Five patients who had CBDE required relaparoscopy for biliary drain-related complications: two for retracted $\mathrm{T}$-tubes, one for difficulty in removing a $\mathrm{T}$ - tube, one to replace a faulty friable T-tube and one to remove the remnant of a transcystic tube broken during removal. Other causes are summarised in Table 3 .

Radiologically guided percutaneous drainage of postoperative abdominal collections was carried out in $17(0.3 \%)$ patients: nine for intra-abdominal abscesses and eight for bile leaks.

\section{Haemostasis}

Five patients $(0.1 \%)$ required simple suturing of bleeding from port sites under local anaesthesia: three at the right subcostal port, one at the umbilical port and one at the right flank port. Two patients with haematological disorders had bleeding from the omentum and the epigastric port and required relaparoscopy for haemostasis. All were elective cases.

Reventilation was necessary for three patients $(0.1 \%)$ post LC either due to severe chest infections $(n=2)$ or due to hypoxia and confusion following initial extubation requiring reventilation for $24 \mathrm{~h}$. All three patients were emergency admission and all recovered well.

\section{Readmission rate}

29 readmissions occurred in the biliary re-intervention group (25.9\%). These resulted from bile leaks in nine patients, retained stone in eight, abdominal collections in four, management of benign stricture in three, T-tube complications in two, abdominal pain in two and one for removal of a retracted drain.

Five 30-day mortalities occurred in this reintervention cohort including the four who suffered mesenteric ischaemia and colonic perforations. Another patient died at a specialist centre from haemorrhage following attempted embolisation of a hepatic artery aneurysm which was suspected during uneventful LC with IOC and subsequently confirmed on CT scan and angiography. 
Table 3 Causes for surgical reintervention

\begin{tabular}{|c|c|c|c|}
\hline Reintervention & Causes & $\begin{array}{l}\text { Clavien-Dindo Classifi- } \\
\text { cation }\end{array}$ & Number $(N=157)$ \\
\hline \multirow[t]{13}{*}{ ERCP } & Retained stone after CBDE & Grade $3 \mathrm{a}$ & $21+12^{* *}$ \\
\hline & Retained stone after LC & Grade $3 \mathrm{a}$ & 5 \\
\hline & Pancreatic cancer ${ }^{*}$ & Grade $3 \mathrm{a}$ & 7 \\
\hline & Periampullary tumour ${ }^{*}$ & Grade $3 a$ & 3 \\
\hline & Benign stricture $^{*}$ & Grade $3 \mathrm{a}$ & $5+9^{* *}$ \\
\hline & Bile leak & Grade $3 a$ & 13 \\
\hline & Suspected retained stone & Grade $3 a$ & 2 \\
\hline & Removal of stent ${ }^{*}$ & Grade $3 \mathrm{a}$ & 14 \\
\hline & Biliary drain related & Grade $3 a$ & 1 \\
\hline & Equivocal cholangiogram & Grade $3 \mathrm{a}$ & 2 \\
\hline & Pancreatic necrosis & Grade $3 a$ & 1 \\
\hline & Post-op jaundice & Grade $3 a$ & 1 \\
\hline & Mirizzi Syndrome III & Grade $3 \mathrm{a}$ & 1 \\
\hline \multirow[t]{7}{*}{ Relaparoscopy } & T-tube related & Grade $3 b$ & 5 \\
\hline & Bile leak & Grade $3 b$ & 5 \\
\hline & Bleeding from omentum & Grade $3 b$ & 2 \\
\hline & Removal of drain & Grade $3 b$ & 1 \\
\hline & Restenting CBD & Grade $3 b$ & 1 \\
\hline & Perforated duodenal ulcer & Grade $3 b$ & 1 \\
\hline & Abscess collection & Grade $3 b$ & 1 \\
\hline Relaparoscopy with ileostomy formation & $\begin{array}{l}\text { Colonic leak from cholecystocolic } \\
\text { fistula }\end{array}$ & Grade $3 b$ & 1 \\
\hline \multirow[t]{2}{*}{ Biliary bypass } & Mirizzi Syndrome IV* & Grade 3b & 1 \\
\hline & Mirizzi Syndrome III & Grade $3 b$ & 1 \\
\hline \multirow[t]{2}{*}{ Biliary reconstruction } & CBD injury & Grade $3 b$ & 2 \\
\hline & Gallbladder cancer* & Grade $3 b$ & 1 \\
\hline \multirow[t]{2}{*}{ Whipple's procedure } & Periampullary tumour ${ }^{*}$ & Grade $3 b$ & 2 \\
\hline & Pancreatic cancer $^{*}$ & Grade $3 b$ & 2 \\
\hline \multirow[t]{2}{*}{ Laparotomy } & Mesenteric ischaemia & Grade 5 & 2 \\
\hline & Perforated large bowel & Grade 5 & 2 \\
\hline \multirow[t]{2}{*}{ Percutaneous drainage } & Abscess collection & Grade $3 \mathrm{a}$ & 9 \\
\hline & Bile leak & Grade $3 \mathrm{a}$ & 8 \\
\hline \multirow[t]{2}{*}{ Gastroscopy } & Removal of stent ${ }^{*}$ & Grade $3 \mathrm{a}$ & 2 \\
\hline & T-tube related & Grade $3 \mathrm{a}$ & 1 \\
\hline Suture under local anaesthesia & Port site bleeding & Grade $3 \mathrm{a}$ & 5 \\
\hline \multirow[t]{2}{*}{ Reventilation } & Chest infection & Grade $4 \mathrm{a}$ & 2 \\
\hline & Hypoxia & Grade $4 \mathrm{a}$ & 1 \\
\hline Chest drain & Pneumothorax & Grade $3 \mathrm{a}$ & 1 \\
\hline Embolisation under interventional radiology & Hepatic artery aneurysm* & Grade 5 & 1 \\
\hline
\end{tabular}

*Reinterventions not due to postoperative complications (47 reinterventions in 23 patients)

**Repeated procedure (12 to remove further retained CBD stone, 9 to remove/change stent for benign stricture)

\section{Discussion}

This study has a reintervention rate due to postoperative complications of $1.6 \%$ in spite of a high emergency workload, routine cholangiography, the adoption of index admission surgery for all comers and single session management of bile duct stones. Although most reinterventions occurred in patients who had undergone bile duct explorations with or without biliary drainage, the incidence of those directly related to biliary drainage was much lower than in studies advocating primary closure of choledochotomies. Reinterventions following single session bile duct exploration have 
to be seen in the context of the complications and reinterventions associated with the currently used staged management of bile duct stones. The reintervention rate in our cohort of patients undergoing LC alone was $0.8 \%$.

A comparison between the group of patients needing reinterventions and the rest of the series shows that certain preoperative characteristics have predictive significance, e.g. emergency admission and presentation with jaundice. Certain operative findings during the original procedure such as difficulty grades 4 and 5 , a contracted gallbladder, bile duct stones necessitating bile duct exploration and the need for open conversion also have significant associations with reintervention (Table 4).

A systematic review was conducted in 2018 including 233 studies to identify range and consistency of definition of reported complications following LC. The study found open conversions to be the most common reported complications (58\% of studies) followed by bile leakage in $38 \%$ and bile duct injury in $32 \% .42 \%$ of the included studies reported reinterventions following LC [9]. This demonstrates that despite LC being the standard treatment for gallstone disease, further reintervention for postoperative complications is occasionally required and should, therefore, be included in the consent process.

Although the current study had a high workload of biliary emergencies and subsequently a high percentage of difficult cholecystectomies, the morbidity rates for the whole study [6] were lower than many published studies [10-16]. Laparoscopic CBDEs were also performed in the emergency cohort with a low reintervention rate compared to other studies on CBDE [11-18] as shown in Table 5.

The benefits of delivering an emergency biliary service in this study are reflected in a low reintervention rate for cholecystectomies done without bile duct explorations. In a cohort of 32,785 LCs, Ros et al. [1] reported a significantly higher incidence of $1 \%$ reinterventions during readmissions within one year of discharge between 1992 and 1995. In addition, reoperations post bile duct surgery, reconstruction or anastomosis between the bile duct and gastrointestinal tract, and reoperation for unspecified reasons were found

Table 4 Demographic, preoperative and operative data of patients requiring postoperative reintervention compared to the rest of series

\begin{tabular}{|c|c|c|c|c|}
\hline Characteristics & $\begin{array}{l}\text { Reinterventions } \\
(n=112)(\%)\end{array}$ & $\begin{array}{l}\text { No reinterventions } \\
(n=5627)(\%)\end{array}$ & $P$ Value & OR $(95 \% \mathrm{CI})$ \\
\hline Gender & & & $p<0.0023$ & $1.80(1.22-2.65)$ \\
\hline Male & $43(38.4 \%)$ & $1444(25.7 \%)$ & & \\
\hline Female & $69(61.6 \%)$ & $4173(74.2 \%)$ & & \\
\hline Emergency admission & $76(67.9 \%)$ & $2478(44.0 \%)$ & $p<0.00001$ & $2.68(1.80-4.00)$ \\
\hline \multicolumn{5}{|l|}{ Primary admission diagnosis } \\
\hline Jaundice & $40(35.7 \%)$ & $897(15.9 \%)$ & $p<0.00001$ & $2.93(1.98-4.34)$ \\
\hline Chronic biliary colic & $33(29.5 \%)$ & $3067(54.5 \%)$ & $p<0.00001$ & $0.35(0.23-0.53)$ \\
\hline Cholangitis & $12(10.7 \%)$ & $115(2.0 \%)$ & $p<0.00001$ & $5.75(3.07-10.76)$ \\
\hline \multicolumn{5}{|l|}{ Operative difficulty grade } \\
\hline Grade 1 & $13(11.6 \%)$ & $1885(33.5 \%)$ & $p<0.00001$ & $0.26(0.15-0.47)$ \\
\hline Grade 2 & $26(23.2 \%)$ & $1717(30.5 \%)$ & $p=0.0962$ & $0.69(0.44-1.07)$ \\
\hline Grade 3 & $21(18.8 \%)$ & $1132(20.1 \%)$ & $P=0.7206$ & $0.92(0.57-1.48)$ \\
\hline Grade 4 & $40(35.7 \%)$ & $784(13.9 \%)$ & $p<0.00001$ & $3.43(2.31-5.09)$ \\
\hline Grade 5 & $12(10.7 \%)$ & $101(1.8 \%)$ & $p<0.00001$ & $6.57(3.50-12.33)$ \\
\hline CBD exploration & $73(65.2 \%)$ & $1245(22.1 \%)$ & $p<0.00001$ & $6.59(4.44-9.77)$ \\
\hline \multicolumn{5}{|l|}{ Gallbladder condition } \\
\hline Acute cholecystitis & $5(4.5 \%)$ & $306(5.4 \%)$ & $p=0.6521$ & $0.81(0.33-2.01)$ \\
\hline Chronic cholecystitis & $47(42.0 \%)$ & $3862(68.6 \%)$ & $p<0.00001$ & $0.33(0.23-0.48)$ \\
\hline Empyema & $12(10.7 \%)$ & $397(7.1 \%)$ & $p=0.1361$ & $1.58(0.86-2.90)$ \\
\hline Contracted & $21(18.8 \%)$ & $624(11.1 \%)$ & $p=0.0110$ & $1.85(1.14-3.00)$ \\
\hline Hartmann's pouch stone & $6(5.4 \%)$ & $41(0.7 \%)$ & $p<0.00001$ & $8.01(3.33-19.30)$ \\
\hline Mucocoele & $10(8.9 \%)$ & $288(5.1 \%)$ & $p=0.0719$ & $1.82(0.94-3.52)$ \\
\hline Conversion to open & $5(4.5 \%)$ & $23(0.4 \%)$ & $p<0.00001$ & $11.39(4.25-30.52)$ \\
\hline Length of surgery, median (range) & $120(32-390) \min$ & $60(15-630) \min$ & & \\
\hline Mortality & $5(4.5 \%)$ & $3(0.1 \%)$ & $p<0.00001$ & $87.60(20.67-371.26)$ \\
\hline Length of hospital stay, median (range) & $16(1-160)$ days & $4(1-100)$ days & & \\
\hline Readmissions & $27(24.1 \%)$ & $153(2.7 \%)$ & $p<0.00001$ & $11.36(7.16-18.04)$ \\
\hline
\end{tabular}




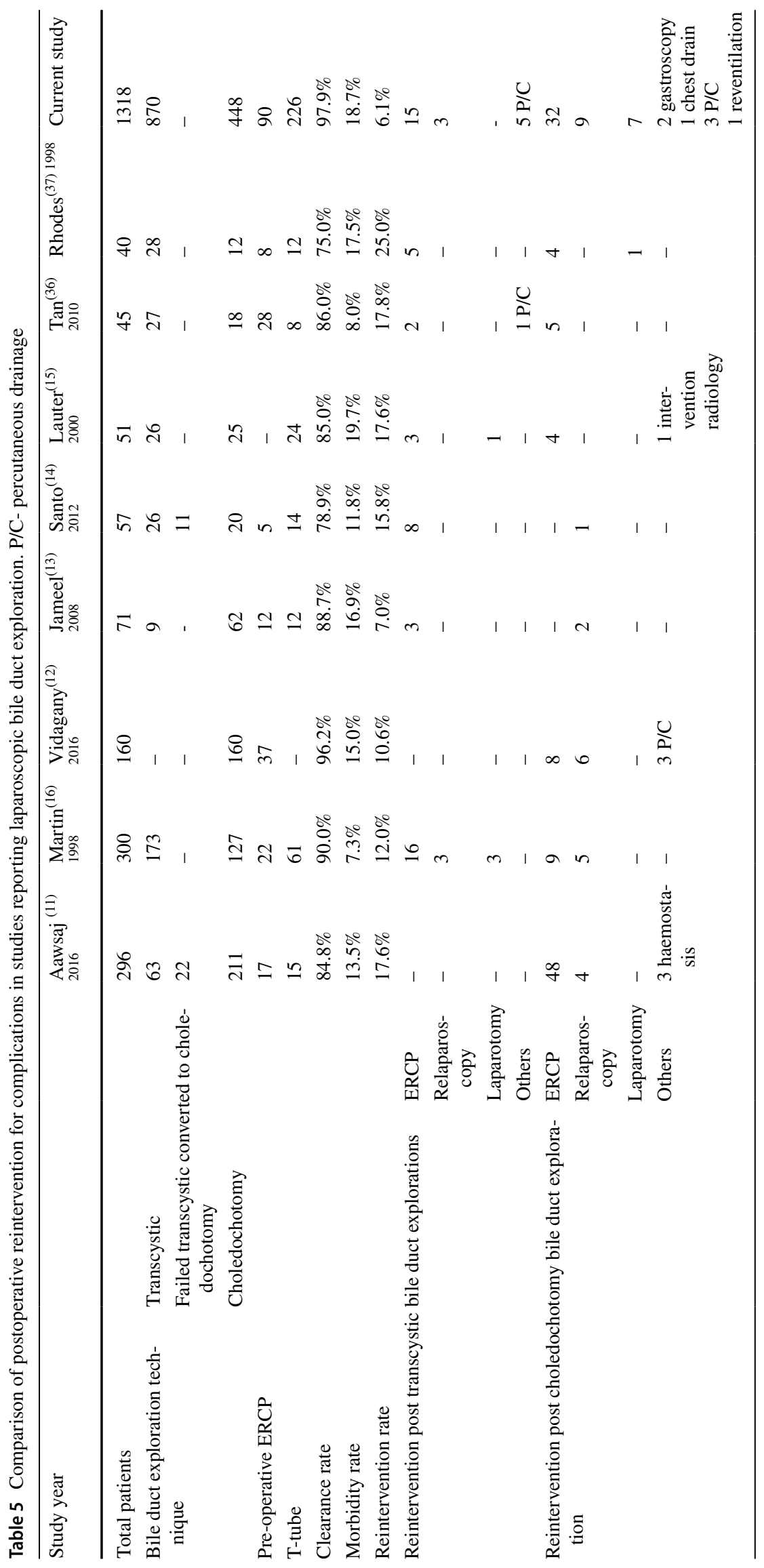


increased upon the introduction of LC. There was a tenfold increase in endoscopic and percutaneous reinterventions compared to open cholecystectomy. However, the data were collected from 1987 to 1995 when most surgeons performing $\mathrm{LC}$ were in the learning phase of the new technique.

In the current study, where IOC is routinely performed, less than $1.6 \%$ of the patients who underwent LC with or without $\mathrm{CBDE}$ had complications requiring reintervention including postoperative ERCP in only $1.1 \%$ of the series. On the other hand, Ragulin-Coyne et al. [19] found that routine IOC was associated with a higher rate of complications and additional cost. However, their complications were mainly due to post-operative infections $(4.3 \%)$ and the additional reintervention procedures (included ERCP in $15.8 \%$ and $\mathrm{CBDE}$ in $2.6 \%$ ). It is likely, therefore, that routine $\mathrm{IOC} \pm \mathrm{CBDE}$, as would be the case in a specialised unit, would have prevented most of these reinterventions. Li J et al. [20] suggested that where routine IOC was performed, one ERCP was avoided for every 18.5 IOCs performed.

Preoperative ERCP remains the main method of clearing CBD stones in most units. However, our results showed that one session laparoscopic management of biliary stones is associated with lower morbidity than published results of ERCP, a finding which was consistent with several studies [18-23]. Kadam et al. [21] reported lower morbidity for LC and CBDE, with bile leakage occurring in $6.7 \%$, while two-stage ERCP/ stenting + LC was associated with $16.7 \%$ pancreatitis and $6.7 \%$ cholangitis. There was a high rate of reintervention in the ERCP group with 2.3 procedures per patient. A systematic review by Kenny et al. [22] concluded that a single-stage approach to managing symptomatic gallstones and CBD stones is the preferred procedure. Rogers et al. [23] prospectively randomised LC and laparoscopic CBDE against ERCP and found that CBDE eliminated the risk of post-ERCP pancreatitis and the need for further procedures. Gupta et al. [24] also found that ERCP involved more reinterventions than one-stage treatment of bile duct stones. Laparoscopic CBDE also reduces the incidence of recurrent stones, thus avoiding inevitable future reinterventions $[25,26]$.

In spite of its benefits, biliary drainage is still a main cause of morbidity following bile duct exploration. In this series of 5740 LC, 527 (9.2\%) had CBDE with biliary drainage (transcystic or T-tubes) resulting in 6 reinterventions (1\%): 5 relaparoscopies and 1 ERCP. However, biliary drainage following choledochotomy helped to minimise the risk of bile leakage, and to obtain postoperative cholangiography. In this study biliary drains were used to clear a few retained stones, flushing the bile duct after Glucagon administration and to dissolve blood clots in the bile duct using Alteplase, a fibrinolytic agent, thus avoiding invasive reinterventions. The use of the T-tube track to remove retained stones was first reported in 1978 by Burhenne [27], but endoscopic reinterventions have reduced the reliance on this technique. On the other hand biliary drains can result in complications. Gillatt et al. [28] reported bile leakage upon removal of the T-tube in $18 \%$ but only one of 39 patients required reoperation due to bile peritonitis. Sharma et al. [29] reported one patient (2.5\%) and Wills et al. [30] had T-tube complications in $15.3 \%$ with a quarter requiring surgical reinterventions. Biliary drain complications are thus associated with a low reintervention rate reflecting the fact that most such complications can be managed conservatively.

12 patients $(0.02 \%)$ in this series were found to have pancreatic, periampullary or gallbladder cancers that required postoperative reintervention. Eight needed ERCP for stenting and 4 underwent Whipple's procedures. In systematic reviews, unsuspected gallbladder cancer was found by Choi et al. [31] in $0.7 \%$ and by Soreide et al. [32] in $0.25 \%-0.89 \%$ routine LCs.

The incidence of bile duct injury varies in the literatures [31-35]. In the current study, two CBD injuries (0.03\%) occurred and were identified intraoperatively. IOC outlined the biliary anatomy and helped to avoid making the injury worse. Biliary stents and abdominal drains were inserted and the patients were referred to a tertiary liver surgery unit where uneventful biliary reconstruction was carried out within $24 \mathrm{~h}$. Tornqvist et al. [36] quoted an incidence of bile duct injury between $0.2 \%$ and $0.9 \%$, while Viste et al. [37] reported a frequency of $0.4 \%$ of main bile duct injury. The low biliary injury rate seems to have been contributed to, at least in part, by routine IOC, which in the context of a specialised service is safe in all elective and emergency patients.

\section{Conclusion}

Reintervention resulting from complications occurred in only $1.6 \%$, in spite of the policy of index admission surgery for all comers including emergency admissions and single session management of bile duct stones. Surgical or endoscopic reinterventions following $\mathrm{LC}$ alone occurred in $0.8 \%$. Some preoperative and operative characteristics are predictive of reintervention and may guide preventive strategies. The most common form of reintervention was ERCP for retained CBD stones. This important outcome parameter of laparoscopic biliary surgery can be optimised through early diagnosis and timely reintervention for complications.

\section{Funding None.}

\section{Declarations}

Disclosures Drs. Ng and Nassar have no conflict of interest or financial ties to disclose. Dr A Nassar performed or personally supervised all operations included in this series. 
Open Access This article is licensed under a Creative Commons Attribution 4.0 International License, which permits use, sharing, adaptation, distribution and reproduction in any medium or format, as long as you give appropriate credit to the original author(s) and the source, provide a link to the Creative Commons licence, and indicate if changes were made. The images or other third party material in this article are included in the article's Creative Commons licence, unless indicated otherwise in a credit line to the material. If material is not included in the article's Creative Commons licence and your intended use is not permitted by statutory regulation or exceeds the permitted use, you will need to obtain permission directly from the copyright holder. To view a copy of this licence, visit http://creativecommons.org/licenses/by/4.0/.

\section{References}

1. Ros A, Haglund B, Nilsson E (2002) Reintervention after laparoscopic and open cholecystectomy in Sweden 1987-1995. Analysis of data from a hospital discharge register. Eur J Surg. 168(12):695-700. https://doi.org/10.1080/00000000000000006

2. Nassar A, Ashkar K, Mohamed A, Hafiz A (1995) Is laparoscopic cholecystectomy possible without video technology? Minimally Invasive Therapy 4(2):63-65. https://doi.org/10. 3109/13645709509152757

3. Griffiths E, Hodson J, Vohra R, Marriott P, Katbeh T, Zino S et al (2019) Utilisation of an operative difficulty grading scale for laparoscopic cholecystectomy. Surg Endosc 33:110-121. https://doi.org/10.1007/s00464-018-6281-2

4. Nassar AHM, Ng H, Wysocki A, Khan K, Gill I (2020) Achieving the critical view of safety in the difficult laparoscopic cholecystectomy: a prospective study of predictors of failure. Surg Endosc 31(2):155-159

5. Nassar A, Nassar M, Gil I, Ng H, Yehia A (2020) One-session laparoscopic management of Mirizzi syndrome: feasible and safe in specialist units. Surg Endosc. https://doi.org/10.1007/ s00464-020-07765-4

6. Nassar AHM, Ng HJ, Ahmed Z et al (2020) Optimising the outcomes of index admission laparoscopic cholecystectomy and bile duct exploration for biliary emergencies: a service model. Surg Endosc. https://doi.org/10.1007/s00464-020-07900-1

7. Nassar AHM, Shallaly G, Hamouda A (2009) Optimising laparoscopic cholangiography time using a simple cannulation technique. Surg Endosc 23(3):513-517. https://doi.org/10.1007/ s00464-008-9853-8

8. Zanati H, Nassar AHM, Zino S, Katbeh T, $\mathrm{Ng} \mathrm{H}$, Abdellatif A (2020) Gall Bladder Empyema: Early Cholecystectomy during the Index Admission Improves Outcomes. JSLS. https://doi.org/ 10.4293/JSLS.2020.00015

9. Alexander H, Bartlett A, Wells C, Hannam J, Moore M, Poole G et al (2018) Reporting of complications after laparoscopic cholecystectomy: a systematic review. HPB 20(9):786-794. https:// doi.org/10.1016/j.hpb.2018.03.004

10. Zhang W, Xu G, Huang Q, Luo K, Tong Z, Li J et al (2015) Treatment of gallbladder stone with common bile duct stones in the laparoscopic era. BMC Surg 15:7. https://doi.org/10.1186/ 1471-2482-15-7

11. Aawsaj Y, Light D, Horgan L (2016) Laparoscopic common bile duct exploration: 15-year experience in a district general hospital. Surg Endosc 30(6):2563-3366

12. Vidagany N, Pozo CD, Tomás N, Ares J, Tarragon A, Masson F (2016) Eleven years of primary closure of common bile duct after choledochotomy for choledocholithiasis. Surg Endosc 30(5):1975-1982
13. Jameel M, Darmas B, Baker A (2008) Trend towards primary closure following laparoscopic exploration of the common bile duct. Ann R Coll Surg Engl 90:29-35

14. Santo M, Domene C, Riccioppo D, Barreira L, Takeda F, Pinotti H (2012) Common bile duct stones: analysis of the videolaparoscopic surgical treatment. Arq Gastroenterol 49(1):41-51

15. Lauter D, Froines E (2000) Laparoscopic common duct exploration in the management of choledocholithiasis. Am J Surg 179(5):372-374

16. Martin I, Bailey I, Rhodes M, O'Rourke N, Nathanson L, Fielding $\mathrm{G}$ et al (1998) Towards T-tube free laparoscopic bile duct exploration: a methodologic evolution during 300 consecutive procedures. Ann Surg 228(1):29-34

17. Tan K, Shelat V, Liau K, Chan C, Ho C (2010) Laparoscopic common bile duct exploration: Our first 50 cases. Ann Acad Med Singapore 39(2):136-142

18. Rhodes M, Sussman L, Cohen L, Lewis M (1998) Randomised trial of laparoscopic exploration of common bile duct versus postoperative endoscopic retrograde cholangiography for common bile duct stones. Lancet 351(9097):159-161

19. Ragulin-Coyne E, Witkowski E, Chau Z, Ng S, Santry H, Callery $M$ et al (2013) Is routine intraoperative cholangiogram necessary in the twenty-first century? A national view. J Gastrointest Surg 17(3):434-442

20. Li J, Puhalla H, Chu F, Li H (2017) Is an IOC Still Necessary During Laparoscopic cholecystectomy? J Surg Oper Care 2(1):102

21. Kadam R, Saxena D, Rana A, Chabra S, Ahmed Z, Vij V et al (2016) Laparoscopic common bile duct exploration versus $\mathrm{ERCP} /$ stenting and cholecystectomy: Is a single staged procedure better? Int J Hepatobiliary Pancreat Dis 6:57-63

22. Kenny R, Richardson J, Mcglone E, Reddy M, Khan O (2014) Laparoscopic common bile duct exploration versus pre or post-operative ERCP for common bile duct stones in patients undergoing cholecystectomy: Is there any difference? Int J Surg 12(9):989-993

23. Rogers S, Cello J, Horn J, Siperstein A, Schecter W, Campbell A et al (2010) Prospective Randomized Trial of LC + LCBDE vs ERCP/S+ LC for Common Bile Duct Stone Disease. Arch Surg 145(1):28-33

24. Gupta N (2016) Role of laparoscopic common bile duct exploration in the management of choledocholithiasis. World J Gastrointest Surg 8(5):376-381

25. Lujian P, Xianneng C, Lei Z (2020) Risk factors of stone recurrence after endoscopic retrograde cholangiopancreatography for common bile duct stones. Medicine (Baltimore). 99(27):e20412

26. Konstantakis C, Triantos C, Theopistos V, Theocharis G, Maroulis I, Diamantopoulou G et al (2017) Recurrence of choledocholithiasis following endoscopic bile duct clearance: Long term results and factors associated with recurrent bile duct stones. World J Gastrointest Endosc 9(1):26-33

27. Burhenne H (1978) Nonoperative instrument extraction of retained bile ducts stones. World J Surg 2:439-445

28. Gillatt D, May R, Kennedy R, Longstaff A (1985) Complications of T- tube drainage of the common bile duct. Ann R Coll Surg Engl 67(6):370-371

29. Sharma M, Chaudhary S, Sharma R, Mahajan A (2016) A prospective study of complications of T- tube drainage of common bile duct in the management of choledocolithiasis in the tertiary care hospital of North India. IOSR JDMS 15(10):9-13

30. Wills V, Gibson K, Karihaloo C, Jorgensen J (2002) Complications of biliary T- tubes after choledocotomy. ANZ J Surg 72(3): 1772-2180

31. Choi K, Choi S, Park P, Kim W, Choi S (2015) Clinical characteristics of incidental or unsuspected gallbladder cancers 
diagnosed during or after cholecystectomy: a systematic review and meta-analysis. World J Gastroenterol 21(4):1315-1323

32. Søreide K, Guest R, Harrison E, Kendall T, Garden O, Wigmore S (2019) Systematic review of management of incidental gallbladder cancer after cholecystectomy. BJS 106(1):32-45

33. Waage A, Nilsson M (2006) Iatrogenic bile duct injury: A population-based study of 152776 cholecystectomies in the Swedish Inpatient Registry. Arch Surg 141(12):1207-1213

34. Karvonen J, Salminen P, Gronroos J (2011) Bile duct injuries during open and laparoscopic cholecystectomy in the laparoscopic era: Alarming trends. Surg Endosc 25(9):2906-2910

35. Eikermann M, Siegel R, Broeders I et al (2012) Prevention and treatment of bile duct injuries during laparoscopic cholecystectomy: The clinical practice guidelines of the European Association for Endoscopic Surgery (EAES). Surg Endosc. 26(11):3003-39
36. Törnqvist B, Strömberg C, Persson G, Nilsson M (2012) Effect of intended intraoperative cholangiography and early detection of bile duct injury on survival after cholecystectomy: population based cohort study. BMJ. 345:e6457

37. Viste A, Horn A, Øvrebø K, Christensen B, Angelsen J, Hoem D (2015) Bile duct injury following laparoscopic cholecystectomy. Scand J Surg 104(4):233-237

Publisher's Note Springer Nature remains neutral with regard to jurisdictional claims in published maps and institutional affiliations. 